\title{
Does Parental Marital Status at Birth Influence the Risk of Children and Grandchildren Requiring Local Authority Care? A Retrospective Study of the Scottish Birth Cohort
}

Michael Colvin ( $\square$ michael.colvin@nhs.scot)

Forth Valley Royal Hospital https://orcid.org/0000-0002-9734-6459

\section{Research Article}

Keywords: Child Health, Social Care, Epidemiology, Statistics, Family structure

Posted Date: December 3rd, 2021

DOI: https://doi.org/10.21203/rs.3.rs-1117486/v1

License: (9) This work is licensed under a Creative Commons Attribution 4.0 International License.

Read Full License 


\section{Abstract \\ Background}

- Demand in children's social care remains at historically high levels across the UK. The number of children in local authority care in Scotland increased every year between 1998 and 2013. This study explores a possible trans-generational influence of historical changes in family structure at birth.

\section{Method}

- Children who were accommodated by a typical Scottish local authority from 2000 to 2013 were identified. The parental marital status on birth registrations of the children and their parents was compared to all Scottish registrations in national birth cohorts and relative risk (RR) was calculated for different birth circumstances.

\section{Results}

- The children who entered care were more likely to have been born to unmarried parents than their peers (RR 7.8, $\mathrm{Cl}$ 6.3-9.6). Their mothers ( $\mathrm{RR} 3.2, \mathrm{Cl}$ 2.7-3.9) and fathers ( $\mathrm{RR} \mathrm{1.5,} \mathrm{Cl} 1.1-2$ ) were also more likely than their peers to have been born to unmarried parents. The accumulated risk of young children entering care if their parents and maternal grandparents had been unmarried on birth registrations was very large (RR 23.3, $\mathrm{Cl} 12.5-43.5)$.

\section{Conclusion}

- Parental marriage is protective against entering local authority care for children in Scotland. Historical changes in family structure at birth may influence demand in children's services.

\section{Introduction}

The proportion of all children involved in social care systems in the four component nations of the United Kingdom has been rising in recent years (figure 1). The number of children in care (looked after away from the parental home) in Scotland increased every year between 1998 and 2013, with a marked increase in the number of children less than 5 years old entering care (19). There is no published research to explain this trend.

Living with a single parent is an important independent risk factor in the epidemiology of children's social care but little is known about other influences of family structure which may be relevant to current demand. 
This retrospective study of the Scottish national birth cohort was undertaken to explore a possible association of the rise in children entering care in Scotland with the rise in childbearing outside marriage from 1977 to 2008, and a possible trans-generational influence of the marital status of grandparents when the parents were born.

Children encounter an excess of health risks before, during and after a period in care and the cost to the public purse of accommodating children is huge $(6,14,20)$. A trans-generational driver for children requiring care would be an important determinant of future social work activity, public spending and health, and could affect the perceived efficacy of measures intended to improve the wellbeing of children.

\section{Method}

The local authority executive authorised a once-only sharing of data with NHS Central Register (NHSCR) in 2013. Scottish children accommodated by the local authority in the years 2000 to 2013 were identified in national birth registrations. The identity and marital status of parents at the time of registering each birth was recorded. Similar information was obtained from parental birth records and the anonymised data returned by NHSCR for analysis.

The children in care (all ages) were considered as a sample of the Scottish birth cohort born 1986 to 2012, and the children accommodated before the age of five years (BLA<5) a sample of the 1996 to 2012 cohort. Relative risk was calculated for parental marital status at birth for the accommodated children and their parents.

Relative risk was also calculated for the combined marital status of parents and maternal grandparents for those children who entered care before the age of five.

Between 1996 and 2012, 55\% of newborn babies had married parents. It was estimated that $50 \%$ of the cohort had married parents and maternal grandparents and $10 \%$ had unmarried parents and maternal grandparents by extrapolating from Scottish births in the period from 1951 to 1995 . The Scottish-born mothers are a sample of this birth cohort (15). The number of siblings was provided by the local authority and the difference between the birth years of mother and child was used for maternal age.

\section{Results}

659 children were identified in the local authority database of looked after children. 590 of these had Scottish birth registrations (all ages). The 69 children whose birth records were not traced in Scottish registers were excluded from statistical analysis.

The median maternal age at birth was 25 years (range 15- 53) and the median number of siblings was one (range 0-4). 
480 out of 590 (81.4\%) of the children with Scottish birth registrations who entered care were born to unmarried parents (Table 1). The Relative Risk (RR) was 7.8 when these children were considered as a sample of the Scottish birth cohort born from 1986 to 2012 (Table 2). 141 (27.2\%) out of 519 Scottish mothers had unmarried parents on birth registrations and 58 (14.9\%) out of 390 Scottish fathers (Table 1). The RR was 3.2 and 1.5 respectively when parents were considered as a sample of the Scottish birth cohort born from 1951 to 1995 (Table 2).

190 children became looked after before the age of 5years (BLA<5), 167 of these had birth registrations in Scotland and 144 also had their mother's birth registration identified (Table 1). The RR of parents, maternal grandparents and paternal grandparents being unmarried were $9.3,4.4$ and 1.7 respectively (Table 2).

Only 12 out of 144 children who entered care before the age of five had married parents and maternal grandparents on birth registrations. 56 had unmarried parents and grandparents on birth registrations (Table 3). This produces the RR of 23.3 when BLA $<5$ is considered as a sample of the Scottish birth cohort born from 1996 to 2012 with mothers a sample of the cohort born 1951 to 1995 (Table 4)

Table 1

\section{Marital status on birth records-}

\begin{tabular}{|c|c|c|}
\hline & all $(\%)$ & $\mathrm{BLA}<5 \mathrm{y}(\%)$ \\
\hline parents married & $110(16.7)$ & $19(10)$ \\
\hline parents unmarried & $480(72.8)$ & $148(77.9)$ \\
\hline child's birth record not traced & $69(10.5)$ & $23(12.1)$ \\
\hline total & $659(100)$ & $190(100)$ \\
\hline maternal grandparents married & $378(57.4)$ & $86(45.3)$ \\
\hline maternal grandparents unmarried & $141(21.4)$ & $58(30.5)$ \\
\hline mother's birth record not traced & $140(21.2)$ & $46(24.2)$ \\
\hline total & $659(100)$ & $190(100)$ \\
\hline paternal grandparents married & $332(50.4)$ & $79(41.6)$ \\
\hline paternal grandparents unmarried & $58(8.8)$ & $20(10.5)$ \\
\hline father's birth record not traced & $269(40.8)$ & $91(47.9)$ \\
\hline total & $659(100)$ & $190(100)$ \\
\hline
\end{tabular}

Table 2 
Relative risk for marital status-

\begin{tabular}{lccccc} 
& \multicolumn{2}{c}{ all } & \multicolumn{3}{c}{ BLA<5 } \\
& RR & $(95 \% \mathrm{CI})$ & $\mathrm{RR}$ & $(95 \% \mathrm{CI})$ \\
& 7.8 & $(6.3-9.6)$ & 9.3 & $(5.8-15)$ \\
$\begin{array}{l}\text { parents unmarried } \\
\text { vs parents married }\end{array}$ & & & & & \\
$\begin{array}{l}\text { maternal grandparents unmarried } \\
\text { vs grandparents married }\end{array}$ & 3.2 & $(2.7-3.9)$ & 4.4 & $(3.2-6.1)$ \\
$\begin{array}{l}\text { paternal grandparents unmarried } \\
\text { vs grandparents married }\end{array}$ & 1.5 & $(1.1-2)$ & & & \\
& & & & &
\end{tabular}

Table 3

Combined marital status of parents and maternal grandparents BLA $<5$ -

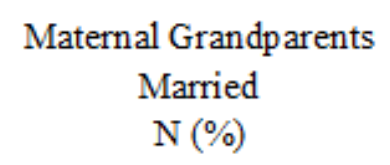

Parents Married

Parents Unmarried

$12(8.3)$

$74(51.4)$
Maternal Grandparents
Unmarried
$\mathrm{N}(\%)$

$2(1.4)$

$56(38.9)$

Table 4

Relative risk for combined marital status-

$$
\begin{gathered}
\text { Maternal Grandparents } \\
\text { Married } \\
\text { RR }(95 \% \mathrm{CI})
\end{gathered}
$$

Parents Married

Parents Unmarried ref

8.8 (4.8 to 16.2$)$

\author{
Maternal Grandparents \\ Unmarried \\ RR $(95 \% \mathrm{CI})$
}

$1.7(0.4$ to 7.4$)$

23.3 (12.5 to 43.5$)$

\section{Discussion}

The high level of activity in child protection services and children's social care across the UK is poorly understood. Recently, concern has been growing about the number of infants and small children being separated from parents and siblings because of child protection concerns and the potentially adverse 
consequences of such early intervention. The repeated removal of newborn infants from vulnerable mothers has drawn particular criticism and calls for change in social work practice $(2,3,14)$.

In England, the Department for Education (DfE) is responsible for overseeing the effective and safe delivery of children's services by local authorities. A review of the DfE by the National Audit Office in 2019 concluded "while the Department has put in place a programme of reform, it still does not fully understand what is driving demand for children's social care or why there is such wide variation between local authorities in their children's social care activity and costs" (6)

In 2021, the independent review of children's social care was announced by the UK government with the aim of improving the children's social care system in England. The preliminary report of the independent review in June 2021 cited rises in parental addiction, mental illness, disability, domestic abuse, unaccompanied asylum-seeking and criminal exploitation as explaining in part why more families are becoming involved in children's social care, and finds a contributory causal relationship between family income, maltreatment and the need for care.

The report also notes heavy caseloads for social workers, remote "risk-averse" decision-making and intergenerational effects. A large proportion of mothers who have had more than one infant accommodated have themselves experienced social care in childhood. Regarding the effect of poverty, MacAlister states "we have now reached a point where the weight of evidence showing a contributory causal relationship between income, maltreatment and state intervention in family life is strong enough to warrant widespread acceptance." Any role of family instability in the requirement for care or as a driver of rising demand is not explored. The remainder of the increase in activity was explained by changes in professional responses to children in need (MacAlister, 2021).

Previous research had established that aggregations of socio-economic risk factors are strongly associated with children entering care. Children living with single mothers of low educational attainment and receiving benefits had a risk of entering care before the age of 7 years of approximately one in seven in a national cohort study of Swedish children (Franzen, 2007). Previously, a child in England of mixed ethnicity in a single parent family receiving benefits for low income was found to have a risk of entering care of approximately one in ten (Bebbington and Miles, 1989). In both studies, living in a single parent family was the largest independent risk factor for children entering care $(1,9)$.

In the UK, absolute poverty in childhood decreased in the years prior to 1979 before levelling off. Relative child poverty (children living in households with income below two thirds of median income) increased markedly in the UK between 1979 and 1996, partly due to a rise in lone parent households. Lone parent households have the least wealth and the lowest incomes of any household type $(8,13,16,17)$.

Trans-generational effects of socio-economic disadvantages have already been proposed in research cited by MacAlister. Using a family stress model, these are said to "operate as acute or chronic factors on the risk of child abuse and neglect, including their impact on the parents' own childhoods." Poverty alone is neither a necessary or sufficient causal factor in the occurrence of child abuse or neglect (Bywaters, 
Bunting, et al., 2016). It follows that trans-generational effects of poverty, family structure, family breakdown and parental drug and alcohol misuse could underlie the aggregation of multiple risk factors in affected families and help explain perplexing trends in the need for social care.

Most established risk factors for children entering care had stabilised in Scotland in the early part of this century. Absolute and relative child poverty was reducing, the rate of births to women under the age of 25 continued a long term decline and the prevalence of alcohol and drug misuse in young adults was stable or improving $(15,16,19,20,21)$. In contrast, the number of children in local authority care (becoming looked after outwith the parental home), having fallen through the 1980s and 1990s, had been steadily rising since 1998, with an associated increase in the number of child protection referrals and court orders for child protection $(18,19)$.

The children being accommodated by Scottish local authorities included a steadily increasing number of infants and young children subject to court orders or entering care because they were considered to be at significant risk of physical and emotional abuse or neglect, often in the context of parental addiction. The number of infants (less than 12 months old) starting to be looked after annually increased from 268 to 753 between 2003 and 2012. The number of children leaving care each year, either returning home or moving into permanent placements, also increased (19).

By $2013,1.8 \%$ of Scottish children were looked after by local authorities or on child protection registers. The total number of children accommodated away from the parental home by Scottish local authorities measured at a single point each year had doubled from 5,349 to 11,282 since 1998 (figure 2).

Noting the marked rise in the number of children entering care in Scotland between 1998 and 2013, the Chief Medical Officer reported that material deprivation was "likely to be a major upstream determinant in the need for care" (20). It was elsewhere speculated that these trends could be explained by an increased awareness of child abuse or changes in practice by professionals in response to high profile child protection failings. Potential drivers of need were not explored in the annual Scottish Government report of Children's Social Work Statistics, and no reference made to changing family structures, recent or historical (19).

In most cultures, parental marriage is considered advantageous for children but the underlying reasons for the apparent benefits are disputed. The association of parental marriage with positive outcomes for children is substantially explained by selection factors such as the parents' income and educational attainment $(5,6,11)$. When many potential confounders were controlled for in a study of children of the UK millennium cohort, small but significant advantages remained in the social and cognitive development of children born to married couples compared with children born to unmarried cohabiting couples (Crawford, Goodman and Greaves, IFS 2013). No substantial research has examined the effects of parental marriage across generations.

In Scotland, the number of births to unmarried parents in 1977 was 5,968 (9.6\% of all births). In subsequent years there was a marked increase in the number and proportion of births to unmarried 
parents. This trend continued until 2008 when births outside marriage reached 30,055 (50.3\%). The number of sole registrations declined during the study period. Joint registrations with parents living at different addresses increased slightly. Most registrations for births to unmarried parents involved cohabiting couples (figure 3).

The peak maternal age at first birth in areas of multiple deprivation in Scotland was twenty years in 2013 (24). A twenty-one year interval between the rising trends of births outside marriage and young children entering care suggests an association of the need for local authority care with material poverty and the marital status of their grandparents when their parents were born. This apparent trans-generational protective effect of parental marriage at population level could be produced by multiple mechanisms.

Compared with children born to married parents, children born to unmarried cohabiting parents experience higher rates of parental separation in childhood. Parental separation, as an adverse childhood experience, can cause damaging psychological stress, increasing the risk of mental illness and addiction. These factors in turn can adversely affect relationship stability and parenting capacity in adults.

The children of single parents have a substantially increased risk of material poverty, low educational attainment, risk-taking behaviours in adolescence and poor quality adult relationships $(5,7,8,11,12,13$, 16). Parental separation, poverty and substance misuse are likely mediators between the grandparents' marital status when the parents were born and the need for social care in grandchildren.

It is reported to be protective for children to have a cohesive family support network. Having married grandparents may be of particular benefit to the children of single parents; either directly, through economic support and child care; or indirectly through the parent having grown up in a stable family unit. Married relationships may also in some way promote the development of healthy behaviours or skills which equip children to become competent parents for the next generation $(5,10,20)$.

In addition there could be an effect of inequitable practice among health professionals, police, social work or courts based on a perceived respectability of married families and assumed protective factors.

The absolute risk for children entering care may be determined by national and local policy, practice and capacity among different agencies well as prevalent socio-economic conditions and levels of maltreatment. Assuming no substantial deviation from national patterns in the local authority which provided the sample data, the absolute risk of entering care under the age of five years for Scottish children with unmarried parents and maternal grandparents may have been greater than $4 \%$ during the period studied.

\section{Strengths And Limitations}

Children who were born in Scotland and entered the care of one Scottish local authority during the study period were included in the analysis. It was not feasible to obtain data sharing agreements with multiple local authorities. The local authority area which provided the data for these children has demographic 
characteristics which are typical for Scotland in most respects. It is centrally located, with a mixture of urban and rural populations. The distributions of age, deprivation and the proportion of births outside marriage are similar to the whole of Scotland and there are no large ethnic groups. Children living in this local authority area are a representative sample of the Scottish birth cohort.

The marital status of parents and maternal grandparents was used to calculate the combined risk for children under five because the birth cohorts sampled for mother and child are well defined. Also, fewer birth registrations were found for fathers and the relative risk for paternal grandparents' marital status alone is barely significant when fathers were considered as a sample of the 1951-1995 birth cohort.

An important limitation of this study is the lack of adjustment for other factors, due to the limited data in birth registrations and considerations of anonymity. Further research could explore more detailed family structure (e.g. sole registration, cohabitation status and parental separation), household wealth and income and the ethnicity of the individuals who enter care and their parents. It will be challenging to determine how much of the increased risk for children is determined by various socioeconomic circumstances affecting their parents but, given the strength of the association, it cannot be possible to determine the effect of poverty and other risk factors without controlling for family structure. This has important implications for future research into children's social care.

\section{Conclusion And Implications}

Parental marriage is a protective factor for the care of children and grandchildren.

Children born to unmarried parents are at greater risk of entering local authority care and of experiencing other effects such as poverty, childhood trauma, addiction or unstable relationships in adulthood, which limit their ability to care for their own children. The sustained rise in the number of young children being taken into care in Scotland beginning around the turn of the century may have been an effect of the increasing number of new parents who were themselves born to unmarried parents. The apparent transgenerational effect of parental marital status at birth is relevant because historic changes in family structure at population level could be a driver of future demand in social care and community health services.

Given the scale of the historical trend towards childbearing outside marriage, a relatively small disadvantage in the care of children could influence demand for services. The relative risk for Scottish children born to unmarried parents in this study is substantial but requires to be adjusted for other factors. The magnitude of the accumulated risk for children born to unmarried parents and maternal grandparents, commensurate with the relationship of cigarette smoking with lung cancer in men, raises the possibility of a causal relationship between family instability and the need for local authority care (23).

It is important to determine if the findings of this study are reproducible in the other parts of the UK, to control for a wider range of socio-economic variables and to monitor these associations over time. There 
is an urgent need for sensitive but detailed research into the effects of changing family structures across generations with regard to the epidemiology of childhood trauma, deprivation, drug and alcohol misuse and the requirement for local authority care.

\section{Declarations}

\section{Acknowledgements}

Thanks for data collection and technical advice to staff at the local authority, NHSCR, National Records of Scotland and Scottish Government and to Professor David Paton of Nottingham University.

Research Ethics Approval The East of Scotland Research Ethics Service deemed formal ethics approval was not necessary under the terms of the Governance Arrangement for Research Ethics Committees.

Funding No specific funding or grants were received by the author.

Conflict of Interest None declared

\section{References}

1. Bebbington \& Miles (1989) 'The Background of Children Who Enter Local Authority Care', British Journal of Social Work

2. Broadhurst, K., \& Mason, C. (2017) 'Birth Parents and the Collateral Consequences of Court-ordered Child Removal: Towards a Comprehensive Framework', International Journal of Law, Policy and the Family

3. Broadhurst, K., \& Mason, C. (2020) 'Child removal as the gateway to further adversity: Birth mother accounts of the immediate and enduring collateral consequences of child removal', Qualitative Social Work

4. Bywaters $P$ et al, (2016) 'The relationship between poverty, child abuse and neglect: an evidence review', Joseph Rowntree Foundation

5. Crawford C, Goodman A and Greaves E, (2013) 'Cohabitation, marriage, relationship stability and child outcomes: final report', Institute of Fiscal Studies

6. Department for Education (2019) 'Pressures on children's social care; National Audit Office report'

7. Dube SR et al (2003) 'Childhood Abuse, Neglect, and Household Dysfunction and the Risk of Illicit Drug Use: The Adverse Childhood Experiences Study', Pediatrics

8. Fergusson D et al (2014) 'Parental Separation/Divorce in childhood and Partnership Outcomes at age 30; Journal of Child Psychology and Psychiatry'

9. Franzen E, (2008) 'The Epidemiology of Out-of-Home Care for Children and Youth: A National Cohort Study', British Journal of Social Work 
10. Friesen MD et al (2017) 'Exposure to Parental Separation in Childhood and Later Parenting Quality as an Adult: Evidence from a 30-year Longitudinal Study', Journal of Child Psychology and Psychiatry

11. Goodman A and Greaves E, (2010) 'Cohabitation and Marriage: Outcomes for Children; Institute of Fiscal Studies'

12. Koball H et al, (2010) 'What Do We Know About the Link Between Marriage and Health?' Journal of Family Issues

13. Institute of Fiscal Studies (1999) 'Poor Kids: Trends in Child Poverty in Britain, 1968-96'

14. MacAlister J. (2021) 'The Case for Change', The independent review of children's social care

15. National Records of Scotland (2020), Vital Events

16. Office for National Statistics (2015) 'Persistent Poverty in the UK and EU, 2008-2013'

17. Office for National Statistics (2016) ' Lone Parent Families in the UK by Country, 1996 to 2015'

18. Scottish Children's Reporter Administration (2013) Annual Report

19. Scottish Government (2014) 'Children's Social Work Statistics Scotland, 2012-13'

20. Scottish Government (2013) 'Annual Report of the Chief Medical Officer 2012'

21. Scottish Government (2012) '2010/11 Scottish Crime and Justice Survey'

22. Scottish Government (2021) 'Children's Social Work Statistics Scotland, 2019-20'

23. Simonato $P$ et al (2001) 'Lung cancer and cigarette smoking in Europe: An update of risk estimates and assessment of inter-country heterogeneity' Int. J. Cancer

24. ISD Scotland (2014) 'Births in Scottish Hospitals; year ending 31st March 2013'

\section{Figures}




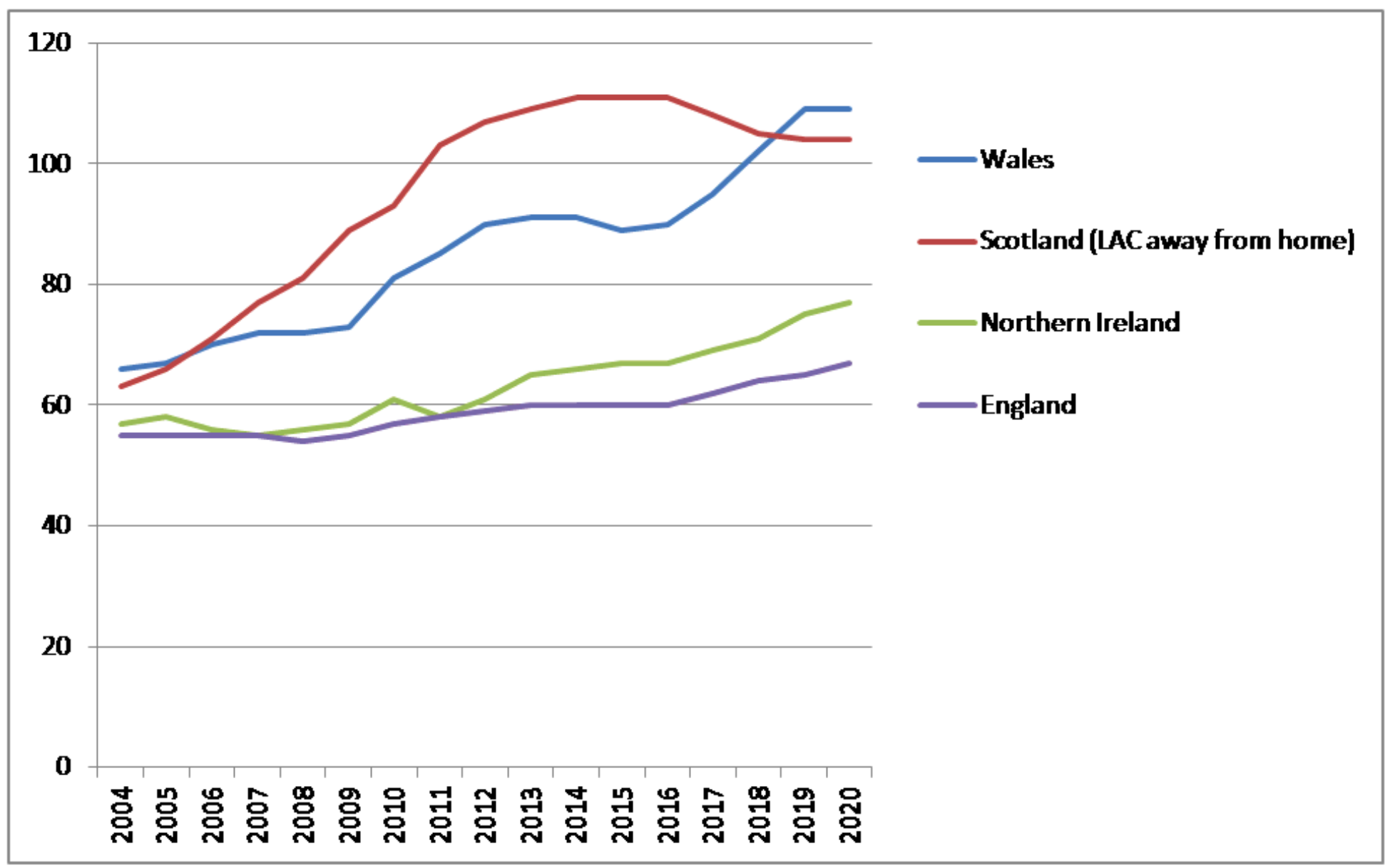

Figure 1

Cross UK comparison of looked after children, rate per 10,000 children under 18, 2004-2020; Scottish Children's Social Work Statistics 2021 (22) 


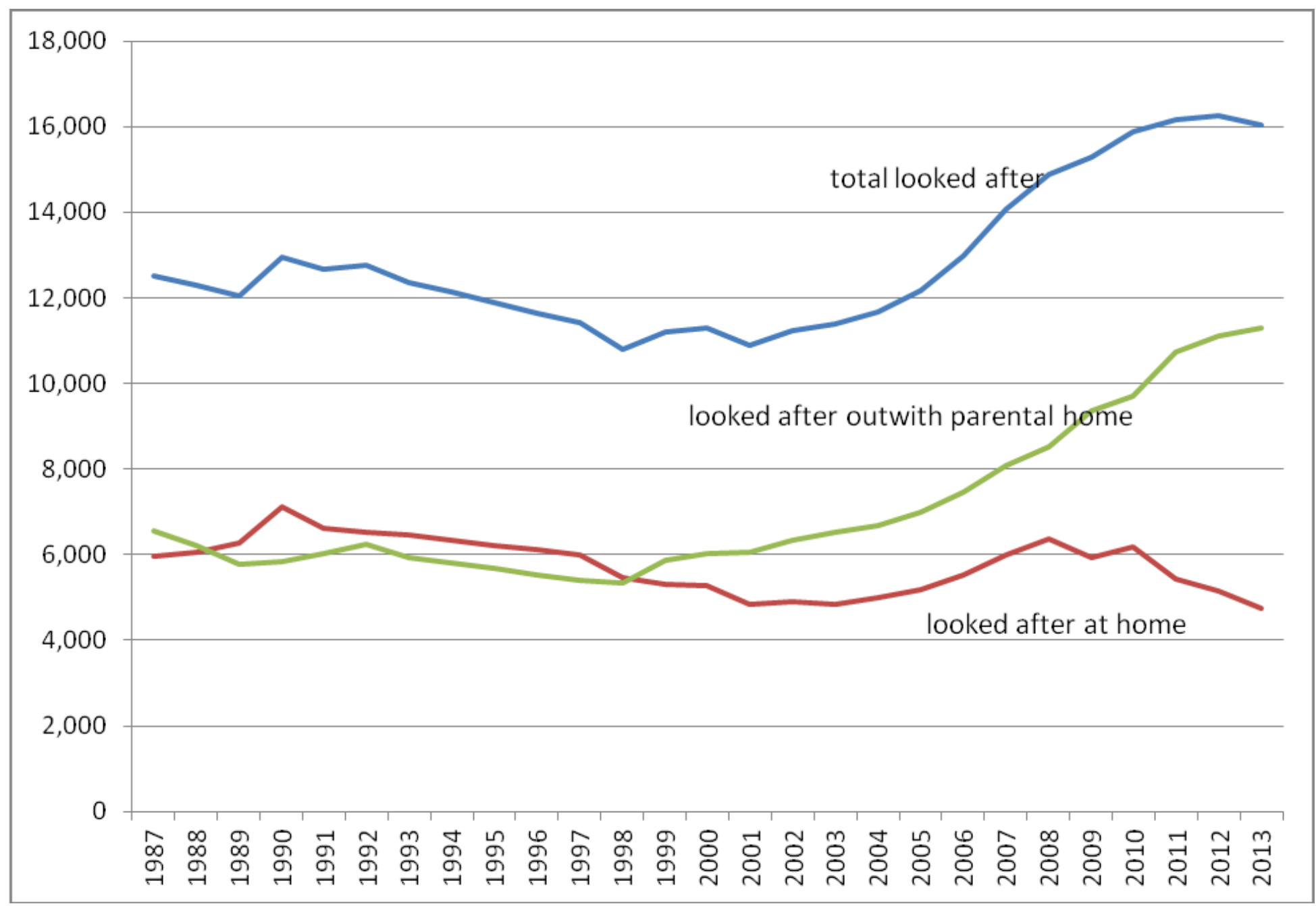

\section{Figure 2}

Number of children looked after by type of accommodation; Scottish Children's Social Work Statistics; 2012-13 (19) 


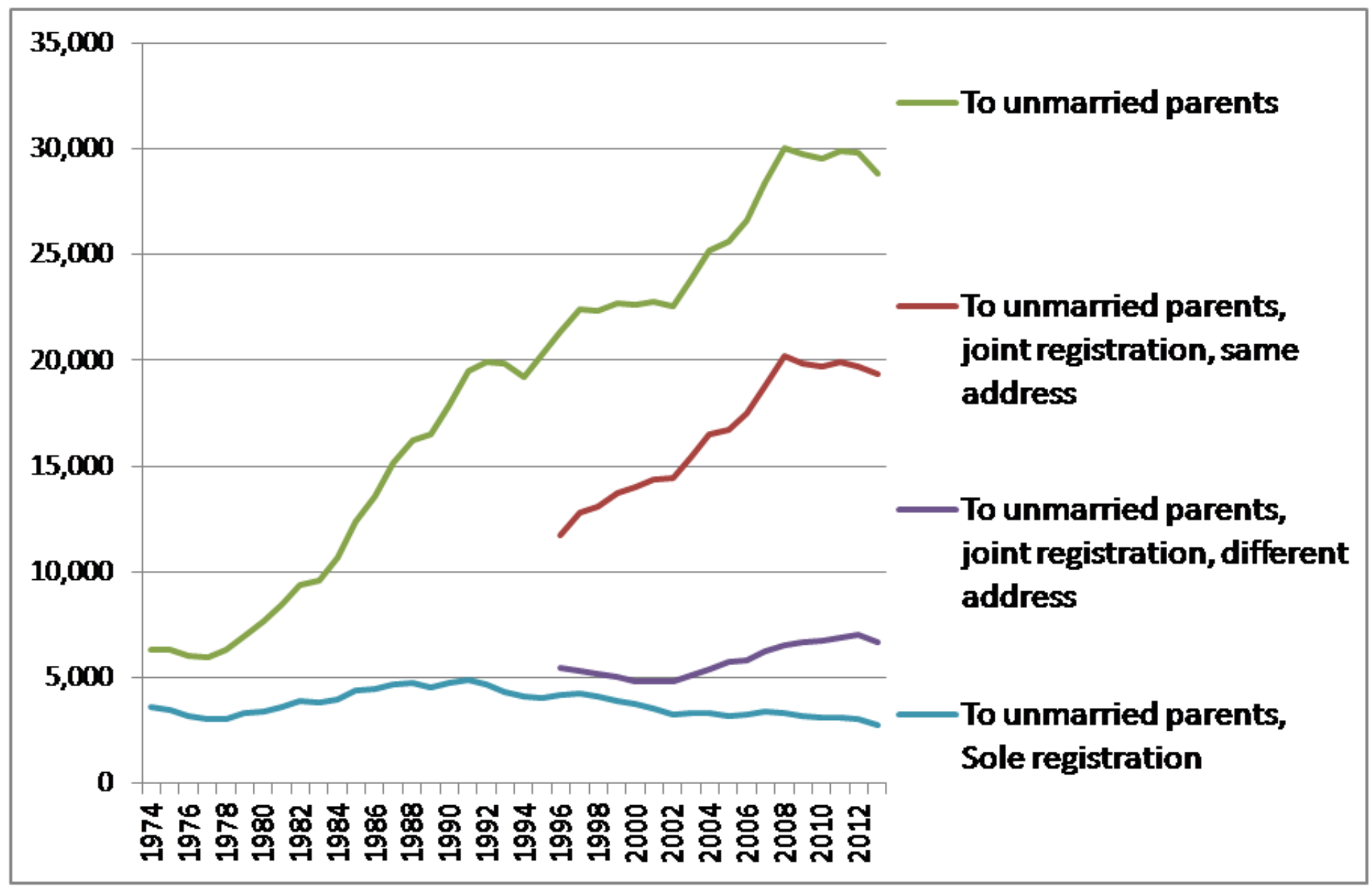

Figure 3

Live births, by marital status of parents and type of registration; 1974 to 2012, data from National Records of Scotland (15) 